University of Exeter Medical School, Royal Cornwall Hospital, Truro, UK

2 Primary care Research Group, University of Exeter Medical School, St Luke's Campus, Exeter, UK

3 Department of Health Sciences, University of York, York, UK

4 REACH-HF Patient and Public Involvement Group, c/o Research \& Development, Royal Cornwall Hospitals NHS Trust, Truro, UK

5 MRC/CSO Social and Public Health Sciences Unit \& Robertson Centre for Biostatistics, Institute of Health and Wellbeing, University of Glasgow, Glasgow, UK

Correspondence to H Dalal h.dalal@nhs.net

Cite this as: BMJ 2021;373:n1270 http://dx.doi.org/10.1136/bmi.n1270

CLINICAL UPDATES

\title{
Virtual and in-person cardiac rehabilitation
}

\section{Hasnain M Dalal, ${ }^{1,2}$ Patrick Doherty, ${ }^{3}$ Sinead TJ McDonagh, ${ }^{2}$ Kevin Paul, ${ }^{4}$ Rod S Taylor ${ }^{5}$}

\section{What you need to know}

- Most eligible patients with coronary heart disease and heart failure do not participate in cardiac rehabilitation. Covid-19 has exacerbated this, with a substantial drop in the number of patients participating

- Home and telehealth based interventions are increasingly being used as alternatives to traditional centre based rehabilitation programmes

- Outcomes for patients participating in home based rehabilitation compare favourably with centre based programmes in terms of hospitalisations, quality of life, and cost

- Telehealth based interventions are promising, but some patients may find these interventions challenging

- Novel ways of delivering rehabilitation have been employed during the covid-19 pandemic, including hybrid models that are likely to be offered as alternatives to centre based rehabilitation in future, enabling greater patient choice and greater uptake of cardiac rehabilitation

Before the covid-19 pandemic, 100 ooo people were admitted to hospital with heart attacks and approximately 200000 were diagnosed with heart failure annually in the UK. ${ }^{1}$ An estimated 7.4 million people in the UK live with cardiovascular diseases, and this is likely to increase with improved survival following coronary heart disease and an ageing population.

A 2020 European position paper, in keeping with other national and international guidelines, ${ }^{23}$ stated that "comprehensive cardiac rehabilitation has been recognised as the most cost effective intervention to ensure favourable outcomes across a wide spectrum of cardiovascular disease." ${ }^{4}$ Benefits include improvements in morbidity, hospital admissions, physical activity, exercise capacity, psychological wellbeing, and health related quality of life. ${ }^{3-11}$

\section{Box 1: Patient groups who benefit from cardiac rehabilitation 4}

\section{High level evidence}

- Post-acute coronary syndrome (ACS), post-primary coronary angioplasty, and coronary artery surgery:

Patients with ACS (class 1, level A, ${ }^{12} 13$ including ST-segment elevation myocardial infarction, non-ST-segment elevation myocardial infarction, and unstable angina (class 1 , level $\mathrm{B}^{12}$ )

- All patients undergoing reperfusion (eg, coronary artery bypass graft, primary percutaneous coronary intervention, and percutaneous coronary intervention (class 1, level $\mathrm{A}^{12}$ )
- Chronic heart failure:

- Patients with newly diagnosed chronic heart failure and chronic heart failure with a step change in clinical presentation (class 1 , level $\mathrm{A}^{10}{ }^{11}$ )

\section{Limited evidence}

- Patients with heart transplant and ventricular assist devices

- Post-valve heart surgery (open and percutaneous)

- Adults and adolescents with congenital heart disease

- Atrial fibrillation

Unlike other international guidelines, evidence informing guidance from the National Institute for Health and Care Excellence is assessed based on Grading of Recommendations, Assessment, Development, and Evaluations (GRADE) criteria-the class/level approach is not used and therefore not referenced above

Patient groups set to benefit are categorised, by evidence level, in box 1 . To achieve these benefits, it is recommended that all core components of cardiac rehabilitation (box 2) are included in a comprehensive programme. ${ }^{4}$ Guidelines from the UK also advocate long term strategies to promote secondary prevention in primary care and service evaluation through audit. ${ }^{3}$

Box 2: Core components of cardiac rehabilitation, according to broad international consensus 4

- Patient assessment

- Clinical history

- Symptoms

- Physical examination

- Investigations: electrocardiogram, cardiac imaging, blood tests

- Physical activity level

- Peak exercise capacity-eg, bicycle ergometer, treadmill, validated walk test

- Physical activity counselling

- Type and level

- Education

- Barriers to exercise

- Exercise for patients unable to engage in walking or cycling based activities

- Exercise training

- Individualised prescribing

- Frequency, intensity, time (duration), and type of exercise (FITT), or FITT related to mealtime (FITT $+\mathrm{T})$

- Diet/nutritional counselling

Assessment 


\section{- Education}

- Healthy food choices

- Weight control management

- Assessment

Education

- Weight reduction

- Lipid management

- Assessment

- Diet, physical activity, and medication

- Blood pressure management

- Assessment

- Lifestyle intervention and medication

- Smoking cessation

- Smoking status, including other tobacco products

- Encouragement to stop smoking all tobacco

- Referral for smoking cessation

- Psychosocial management

- Assessment of psychosocial risk factors

- Referral for behavioural and psychosocial intervention

- Vocational reintegration/return to work

- Evaluation of programme results

- Determination of success and failure of interventions

- New rehabilitative goals

- Communication regarding continuing care

- Quality assurance using systematic registration

- Structured follow-up

Even before the covid-19 pandemic, most patients in high and low to middle income countries were not offered cardiac rehabilitation 514 and uptake was low. Lockdown measures owing to covid-19 have exacerbated this problem. ${ }^{15}{ }^{16}$ Provision and use of cardiovascular healthcare have decreased worldwide, with substantial numbers of patients in Europe and North America unable to access routine hospital care. ${ }^{1516}$ In the UK, covid-19 shielding guidance for patients with cardiovascular disease and redeployment of NHS staff to acute services have notably reduced access to and use of these services. ${ }^{17}$

This clinical update describes pre-pandemic evidence for cardiac rehabilitation and considers how adoption of a broader range of evidence based delivery methods can improve uptake and patient outcomes during the pandemic and beyond.

\section{Cardiac rehabilitation before the pandemic}

Historically, rates of referral to cardiac rehabilitation were suboptimal in the US ${ }^{1819}$ and UK ( $<15 \%$ for heart failure). ${ }^{20}$ Uptake was also poor, with only 68074 (50\%) of the 135861 patients with coronary heart disease in England, Wales, and Northern Ireland accepting an offer of cardiac rehabilitation in the 12 months before the pandemic. ${ }^{21}$

Most patients referred for rehabilitation after a cardiac event were offered supervised, group based classes, which ranged in frequency, intensity, duration of exercise, and self-help guidance. ${ }^{421}$ Cardiac rehabilitation was usually delivered in hospital outpatient departments or community centres, or (in some parts of Europe) as inpatient services. ${ }^{4}$ Collectively, these modes of delivery are termed “centre based cardiac rehabilitation.” Despite compelling evidence for clinical and cost effectiveness, participation in centre based programmes remained suboptimal, with overall participation rates $<20 \%$ in the US ${ }^{22}$ and similar rates after a diagnosis of heart failure in Europe. ${ }^{23}$ Poor participation predominated in certain groups: women, older people, ethnic minorities, and those living in rural communities or who are socioeconomically deprived. 42124

Consequently, calls were made for alternatives to centre based cardiac rehabilitation. ${ }^{25}$ Suggested interventions included rehabilitation at home facilitated by healthcare professionals and supported by telehealth technologies, to improve uptake. ${ }^{26}$ An American scientific statement in 2019 advocated home based cardiac rehabilitation, ${ }^{9}$ and guidance from the National Institute for Health and Care Excellence (NICE) on chronic heart failure in the UK in 2018 stated that "delivery of home based rehabilitation may increase access and uptake. ${ }^{27}$ Hybrid models involving a combination of home and centre based rehabilitation have been evaluated ${ }^{28}$ but not implemented widely. ${ }^{9}$ Tele-rehabilitation-“rehabilitation from a distance by using one or several devices monitoring and communicating patient specific information to the caregivers," 29 which often involves telephones, videoconferencing, and mobile apps (telehealth) ${ }^{30}$-is increasingly used, often as an adjunct to home based rehabilitation.

Box 3 summarises key national and international recommendations on cardiac rehabilitation. Box 4 discusses ways to improve delivery of cardiac rehabilitation for patients, including under-represented populations.

\section{Box 3: Key recent recommendations on cardiac rehabilitation}

\section{World Health Organization}

- In 2017, WHO issued a statement committing to key actions to strengthen cardiac rehabilitation services and highlighted the evidence indicating the benefits of rehabilitation after acute myocardial infarction. ${ }^{31}$ Rehabilitation should be "part of universal health coverage and should be incorporated into the package of essential services, along with prevention, promotion, treatment, and palliation" 31

UK

- The 2018 NICE guidance on chronic heart failure states that rehabilitation "should be provided in a format and setting (at home, in the community, or in the hospital) that is easily accessible for the person" 27

- The NHS Long Term Plan similarly underlines the importance of rehabilitation and has set an ambitious target of $85 \%$ of eligible patients being able to access care by $2028^{32}$

- The importance of cardiac rehabilitation and delivering cardiac rehabilitation during the covid-19 pandemic is discussed in a cardiovascular disease impact report by NICE in 2021. https://www.nice.org.uk/Media/Default/About/what-we-do/Intopractice/measuring-uptake/cvd-impact-report/nice-impact-cvdmanagement.pdf

US

- In response to the covid-19 outbreak, the American Association of Cardiovascular and Pulmonary Rehabilitation has established the Innovative Delivery Model Collaborative to facilitate digital approaches and encourage home based delivery of rehabilitation. It offers webinars on virtual cardiac and pulmonary rehabilitation. https://www.aacvpr.org/Learn/Learning-Center/Virtual-Rehab-Module-Series

- A US scientific statement from 2019 noted that only a minority of eligible patients participate in rehabilitation and recommended home 
based interventions for low to moderate risk patients unable to access centre based programmes 9

- In 2016, the Million Hearts Cardiac Rehabilitation Collaborative of 100 organisations developed a road map to increase participation in rehabilitation from $20 \%$ to $70 \%$ by $2022^{19} 24$

\section{Europe}

- A2020 European position paper focuses on centre based programmes but does not comprehensively consider home based interventions 433

- A paper from the European Association of Preventive Cardiology on recent cardiac tele-rehabilitation studies provides a practical guide for the setup of rehabilitation services during the covid-19 pandemic ${ }^{16}$

\section{Covid-19}

- The emergence of covid-19 has prompted calls for accelerated introduction of alternative methods of delivery that include home based and tele-rehabilitation options ${ }^{15} 163034$

\section{Box 4: Improving delivery of care for patients, including} under-represented populations

\section{Increasing referral to cardiac rehabilitation}

- Referral to cardiac rehabilitation can be increased through automatic referral at discharge, which can be enhanced by informing the patient of the benefits of the intervention 182535 and by making referral a "quality of care indicator" 36

\section{Addressing health inequalities}

- Engagement with cardiac rehabilitation is determined by service level and patient level factors-for instance, age, sex, ethnicity, level of deprivation, timing of rehabilitation, and mechanism of referral 37

- Economic evaluations of data from the British Heart Foundation National Audit of Cardiac Rehabilitation confirm uptake rates of $37.6 \%$ and $51.7 \%$ for the most and least deprived populations, respectively 37

- Patients who are given a firm date to attend their initial rehabilitation assessment are more than four times more likely to engage in rehabilitation programmes ${ }^{38}$

- Covid-19 has exacerbated health inequalities, with poor outcomes in marginalised populations, and has prompted calls to establish equitable care models "that build culturally appropriate communication and outreach practices to communicate with patients beyond traditional phone calls and office visits" 39

- Lower rates of digital literacy and access have also been reported in other marginalised groups during the pandemic. ${ }^{39}$ Differences in the digital literacy of the healthcare workforce also need to be

considered..$^{40}$ Further research on implementation of telehealth and home based approaches in cardiac rehabilitation is urgently needed to inform providers and commissioners. ${ }^{29} 41$

\section{Cardiac rehabilitation during the pandemic}

The number of patients with heart failure in the UK participating in rehabilitation decreased from 4969 ( $<10 \%$ of eligible patients) before the pandemic (May 2019-January 2020) to $1474(<5 \%$ of eligible patients) during the first wave (February-August 2020)..$^{42}$ Analysis by the British Heart Foundation (BHF) published in 2020 mirrored other cardiac audits, showing a 30-40\% decrease in use of cardiology and rehabilitation services because of the pandemic compared with a similar period in 2019. ${ }^{17} 43$ Covid-19 has therefore led to further calls for alternatives to traditional centre based cardiac rehabilitation programmes, with an emphasis on home based and digital technologies to provide virtual access. ${ }^{15} 16$
Indeed, although overall uptake of cardiac rehabilitation has decreased, the proportion of patients receiving home based rehabilitation in the UK has increased more than threefold since the pandemic-from $22.2 \%$ to $72.4 \%{ }^{42}$-as more services began to offer home based and remote delivery. ${ }^{17}$ The rapid adoption of technology in response to suspension of centre based rehabilitation in the pandemic was also reported in an international survey of 330 cardiac rehabilitation healthcare professionals. ${ }^{44}$ Use of tele-rehabilitation can provide "a safe solution for patients, family, and staff in the midst of covid-19."30 Examples of how programmes have adapted the delivery of rehabilitation in the pandemic have been shared by NICE. ${ }^{45} 46$ Reporting by the BHF on modes of delivery in response to covid-19 now includes greater detail on 11 different cardiac rehabilitation interventions, including nine types of home based, virtual, and hybrid programmes. ${ }^{17}$

\section{Box 5: Practical tips for remote/virtual delivery of cardiac rehabilitation ${ }^{15}$}

- Make it easy

- Use tip sheets to help staff adjust to delivering care virtually

Avoid becoming overwhelmed by the multitude of available resources by finding a single, comprehensive, verified online resource for patients and staff

\section{- Don’t wait}

- Encourage patients to attend at minimum intake assessments to discuss the merits of virtual cardiac rehabilitation

- Follow a shared decision making process for enrolment in virtual rehabilitation, to ensure patients understand potential risks and benefits of participating virtually versus choosing to delay care

- Focus on core components*

- Consider lifestyle risk management, psychosocial support, medical advice, education

- Provide simple exercise prescriptions aimed at encouraging low-to-moderate physical activity

- Obtain patient metrics

- Examples include a self-administered six minute walk test for exercise capacity, using patients' personal scales and blood pressure cuffs

- Offer group sessions

- Reduce "labour intensive" one-to-one sessions when possible by providing group tele-/video-conferencing for educational sessions and patient support

- Evaluate

- Formalise an evaluation process to assess the merits and efficacy of virtual care

- Invest in access

- For rural and/or under-resourced areas, consider purchasing tablets, smartphones, or other electronic options for loan to participants to enhance a one-to-one personal experience

*Moulson et al suggest that it is possible to complete assessment of the core components digitally/virtually, including an exercise test, albeit with the limitations ${ }^{15}$

\section{How can exercise capacity be assessed remotely during the pandemic?}

Baseline assessment of exercise capacity is core to the effective and safe delivery of exercise interventions. ${ }^{3}$ In the UK, the incremental shuttle walk test, step test, and six minute walk test are part of 
routine practice ${ }^{3}$ and are monitored by local programmes and reported nationally through the BHF audit. In response to covid-19, most cardiac rehabilitation programmes have adjusted assessments to include greater use of submaximal step tests, two and three minute walk tests, and other more subjective approaches, including physical activity questionnaires (eg, the Duke Activity Status index), fitness apps, and observation of patients carrying out activities such as chair based exercise or using hallways and stairs at home.

Several publications from North America and Europe discuss how to adapt and use different baseline fitness tests to assess the relative risk of exercise. ${ }^{15} 163047$ Risk assessment to determine whether patients have a fitness level below five metabolic equivalents and a proportional response (eg, heart rate and rating of exertion) to exercise is a key focus ${ }^{15} 4748$ (box 5). Such changes are envisaged as temporary adjustments, 47 as programmes had already started to reintroduce fitness tests before the January 2021 lockdown in the UK. However, robust studies of innovations-driven by covid-19-in home based assessment of exercise capacity could validate them for the future portfolio of exercise tests.

\section{How do home and centre based cardiac rehabilitation programmes compare?}

The UK, Australia, and Canada have been key adopters of home based cardiac rehabilitation. ${ }^{9}$ In the UK, the Heart Manual-acknowledged as the "most extensively studied self-management programme" "-has been used by the NHS for more than 10 years. Box 6 lists advantages and disadvantages of home based cardiac rehabilitation.

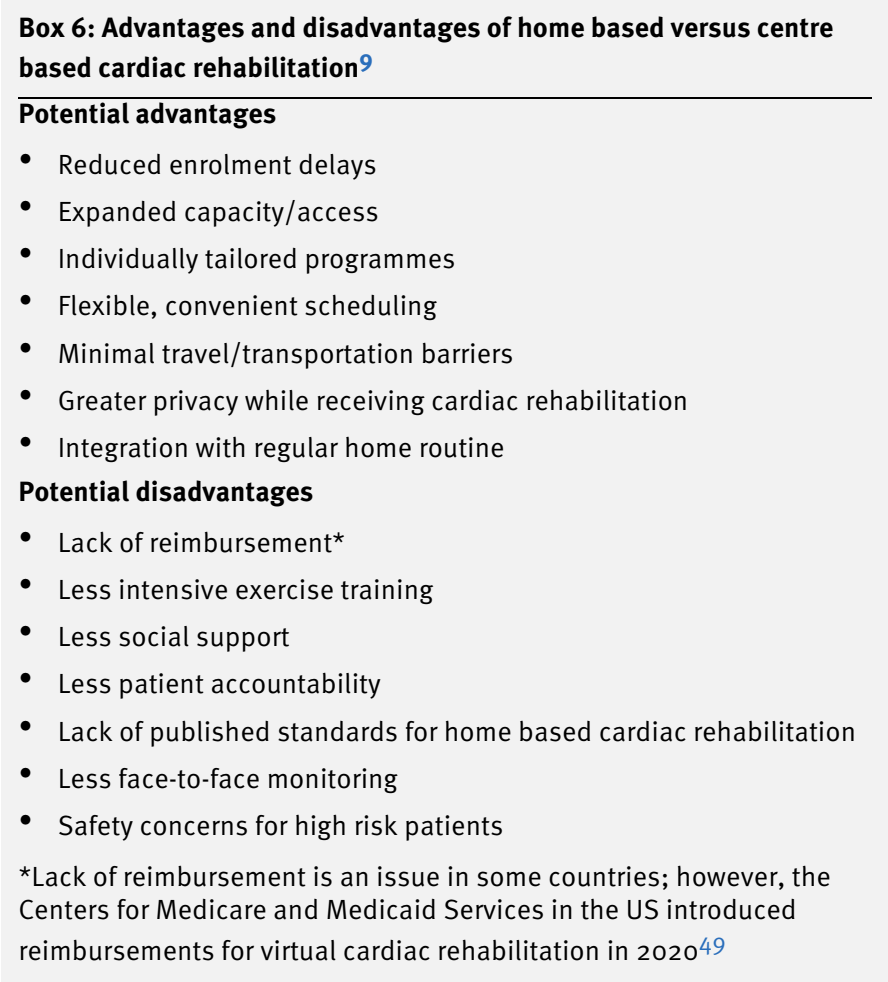

The standards and core components (box 2) used in many home based cardiac rehabilitation studies are comparable with those in studies of centre based interventions). ${ }^{9}$ Cochrane reviews in coronary heart disease and heart failure consistently report statistically significant reductions in hospital admissions with centre and home based cardiac rehabilitation compared with usual care. ${ }^{5}$ In an updated Cochrane review that included 44 randomised controlled trials (10 home based and 34 centre based), the relative risk reduction for all cause hospitalisation was 0.70 ( $95 \%$ confidence interval (CI) o.6o to o.83)). Studies that directly or indirectly compared home and centre based cardiac rehabilitation found no statistically significant difference in 12 month mortality between the two approaches. ${ }^{6-9}$ A systematic review of 31 randomised controlled trials reported that home based and hybrid cardiac rehabilitation models can improve exercise capacity and are potential alternatives to centre based programmes. ${ }^{50}$

A meta-analysis of individual participant data and the updated Cochrane review showed that participation in home or centre based cardiac rehabilitation after heart failure resulted in a clinically meaningful improvement in health related quality of life, determined using the Minnesota Living with Heart Failure questionnaire score (7.1 (95\% CI -3.7 to -10.5)), compared with no rehabilitation. ${ }^{6}{ }^{1}$ Improvements in health related quality of life were reported for 11 of 13 trials of home versus centre based cardiac rehabilitation using various validated questionnaires, with no statistically significant difference between the two groups. ${ }^{9}$

Improvements in modifiable cardiovascular risk factors with cardiac rehabilitation are documented in a US scientific statement. ${ }^{9}$ Differential effects on weight, blood pressure, lipids, and tobacco use were similar in the eight home versus centre based cardiac rehabilitation trials that were included (fig 1$){ }^{9}$

Adherence to home based cardiac rehabilitation is comparable with that in centre based programmes; however, considerable variation is seen in reporting of adherence, and the US scientific statement noted limited ability to pool data to compare home and centre based programmes. ${ }^{9}$ No statistically significant difference in adherence was reported between the two settings in a Cochrane review that included seven studies; however, three of the studies showed better adherence to home than centre based cardiac rehabilitation (RR 1.04 (95\% CI 1.01 to 1.05); $\mathrm{P}=0.009) .{ }^{7}$ A small qualitative study nested within a randomised controlled trial reported that most patients, given the choice, prefer home based cardiac rehabilitation $(57 \%$ versus 43\%)..$^{52}$ Indeed, European and NICE guidelines recommend home based rehabilitation with or without telemonitoring, as evidence suggests that home based programmes can increase participation and support behaviour change. ${ }^{227}$ A large prospective cohort study of 151 centres with 99097 patients in the US reported that patients referred to home based cardiac rehabilitation were four times more likely to participate than those offered centre based programmes. ${ }^{953}$ In response to covid-19, the Centers for Medicare and Medicaid Services in the US introduced reimbursements for virtual and home based cardiac rehabilitation from October 2020. 49

A Cochrane review concluded that clinical benefits with centre and home based cardiac rehabilitation in patients with heart failure, myocardial infarction, and coronary revascularisation are similar and with equivalent costs. ${ }^{7}$ In this and the updated Cochrane review of rehabilitation for adults with heart failure, gains in health related quality of life and costs between home and centre based rehabilitation were also comparable. ${ }^{67}$ Box 7 summarises the evidence for the cost effectiveness of home based programmes.

\section{Box 7: Cost effectiveness of home based cardiac rehabilitation and} tele-rehabilitation

- A systematic review that examined economic evaluations in cardiac rehabilitation published since 2001 concluded that cardiac rehabilitation was cost effective compared with usual care 54

- Incremental cost effectiveness ratios (ICERs) ranged from $\$ 1065$ to $\$ 71755$ ( $f 751$ to $£_{50} 648$; $€ 869$ to $€ 58557$ ) per quality adjusted life year (QALY), although no significant differences in costs and 
QALYs were reported in two studies that directly compared home and centre based rehabilitation 54

- Tele-rehabilitation was used in four included studies and was considered to be cost effective in all, but with wide ranging ICERs (from dominant (cardiac rehabilitation less costly and more effective than usual care) to $\$ 588734$ per QALY) 54

- The authors called for larger studies to strengthen the evidence base, observing a potential reduction in costs if tele-rehabilitation were more widely adopted and noting that patient adherence to digital technologies is variable 54

- Health economic modelling based on a recent multicentre trial in patients with heart failure concluded that home based cardiac rehabilitation can be cost effective in the health service setting in the UK55

- A facilitated home based cardiac rehabilitation intervention for people with heart failure and their caregivers: a research programme including the REACH-HF RCT 56

\section{How do tele-rehabilitation and centre based cardiac rehabilitation programmes compare?}

Tele-rehabilitation interventions are promising and are replacing centre based programmes as part of home based approaches during the pandemic. ${ }^{30}$ In a trial of 162 adults with coronary heart disease, which compared the effects of remotely monitored rehabilitation (by smartphone and web apps) with centre based programmes, remote cardiac rehabilitation was "an effective, cost efficient alternative delivery model that could improve overall utilisation rates by increasing reach and satisfying unique participant preferences." ${ }^{57}$ However, caution is urged when implementing telehealth based interventions, as the mean age in most studies is less than 60 years. Some patients may find such interventions challenging without facilitated support. ${ }^{429}{ }^{41}$ Ensuring quality assurance with telehealth based modes of delivery is also potentially challenging. ${ }^{16} 29$

A systematic review and meta-analysis that included 30 telehealth trials of secondary prevention in patients with coronary heart disease reported statistically significant lower re-hospitalisation and cardiac events (RR 0.56 (95\% CI 0.39 to 0.81 ), $\mathrm{P}<0.0001$ ) in the intervention groups. The authors concluded that telehealth interventions could be offered to patients unable to attend centre based rehabilitation..$^{8}$

Another meta-analysis, which reviewed 11 trials $(\mathrm{n}=1189)$, reported that telehealth interventions were at least as effective as centre based programmes for improving modifiable cardiovascular risk factors and exercise capacity. ${ }^{59}$ Adherence to exercise was significantly higher with telehealth (fixed effect standardised mean difference 0.75 (95\% CI 0.52 to 0.98$)$ ). ${ }^{59}$ Telehealth rehabilitation programmes can also quantify adherence to home based programmes through wearable accelerometer devices linked to the internet. ${ }^{9}$

\section{Conclusion}

Poor rates of participation in conventional cardiac rehabilitation programmes led to the development of home based and digitally delivered interventions, which are supported by emerging evidence. Covid-19 has provided an opportunity "to reimagine how cardiac rehabilitation is delivered." 49 In the future, patients with cardiovascular disease are likely to be offered alternatives to centre based cardiac rehabilitation, including hybrid models, which will provide patient choice ${ }^{52}$ and should increase overall uptake in keeping with ambitious national targets in the US and UK. ${ }^{19}{ }^{32}$

\section{Education into practice}

- How well do you know the local pathways to refer patients for home based cardiac rehabilitation after a heart attack or new diagnosis of heart failure?

- In patients with a new diagnosis of heart failure, how many have been referred to and participated in a cardiac rehabilitation programme in the past 12 months?

\section{Ongoing research and unanswered questions}

\section{Ongoing research}

- The National Institutes for Health Research (NIHR) Health Technology Assessment (HTA) Programme is funding a study based in the UK: A randomised controlled trial of a facilitated home based rehabilitation intervention in patients with heart failure with preserved ejection fraction and their caregivers: the REACH-HFpEF Study (2021-2024) ${ }^{60}$

- The Western Norway Health Authority has funded a study of 3000 patients offered cardiac rehabilitation after a percutaneous coronary intervention, ${ }^{61}$ which will allow comparison of outcomes with another study on hospitalisation of older adults after acute myocardial infarction $^{62}$ : Rethinking rehabilitation after percutaneous coronary intervention: a multicentre cohort study on continuity of care, health literacy, adherence, and costs at all care levels (the CONCARDPCI) study ${ }^{61}$

- The Improving ATTENDance in Cardiac Rehabilitation Trial (iATTEND) $(2019-23)^{63}$ : A randomised trial of 270 patients in the US to assess the efficacy of a hybrid approach to delivery of cardiac rehabilitation on attendance by combining both centre based and remote or home based cardiac rehabilitation sessions. The intervention group combines centre based and remote/home based cardiac rehabilitation and is tailored to the individual needs of each patient, accomplished with the assistance of an easy-to-access telecommunications method (telemedicine)

\section{Unanswered questions 4964}

- What is the impact of

- home based services in more diverse and higher risk groups of patients?

- hybrid models of cardiac rehabilitation, including components from both centre and home based settings?

- What are the barriers for using digital health technologies including wearable monitoring devices for cardiac rehabilitation in terms of factors that are

- patient related?

- clinician related?

- legal and ethical issues?

- interoperability and technical issues?

- lack of reimbursement?

- What study designs should be used to evaluate multimorbidity cardiac rehabilitation programmes?

- What is the feasibility of delivering cardiac rehabilitation through primary care networks?

- Can we improve inequality in the uptake of cardiac rehabilitation by culturally adapting programmes for ethnic minority groups? 


\section{How patients were involved in the creation of this article}

Cindy Edgeler is married to Chris, a retired roadman with Cornwall Highways, who was admitted to hospital with a heart attack in 2012 (Box "A carer's story by Cindy Edgeler"). Chris was a patient of coauthor HD, and both Cindy and Chris were members of the Patient and Public Involvement Group that was part of the Rehabilitation Enablement in CHronic Heart Failure (REACH-HF) National Institute for Health Research (NIHR; RP-DG-0709-10111) funded clinical trial. Cindy and Chris reviewed a draft version of the clinical review.

We also received feedback from patients supported by the Wirral Community Cardiology Service, who have been delivering REACH-HF since 2019 and throughout the COVID-19 outbreak.

https://www.nice.org.uk/sharedlearning/delivering-rehabilitation-enablement-in-chronic-heart-failure-reach-hf-in-wirral

Our patient coauthor KP has been a member of the REACH-HF study group for several years, having had a heart attack in 2008. KP reviewed and provided input to this manuscript and talks about his experience of receiving CR in a podcast from our 2015 BMJ clinical review, which is available at: https://soundcloud.com/bmjpodcasts/cardiac-rehab-patient.

Our patient advisers acknowledged the usefulness of the digital approach to cardiac rehabilitation, especially for those who struggle to get to centre based sessions. But they also highlighted the need for a more hybrid approach so that rehabilitation is as accessible as possible. The final manuscript was modified to reflect the patients' views.

\section{A carer's story, by Cindy Edgeler}

My husband had a heart attack in 2012, which also left him with heart failure. After having stents fitted on the day he was admitted to hospital, he was well looked after on the critical care ward, and then came home. Although he received good aftercare, I felt that I had no support and was left to my own devices. I had many questions, worries, and fears. I would lie next to him at night while he slept and wonder if each breath would be his last. He would say: "Stop asking me if I'm alright."

There was no one I felt I could talk to, and I needed reassurance.

A few months later, we were offered the Rehabilitation Enablement in CHronic Heart Failure (REACH-HF) home based cardiac rehabilitation programme and were presented with the Heart Failure Manual and Family \& Friends Resource for Carers, which importantly linked me to a nurse facilitator. From the first meeting there was a stark contrast with our previous experience, in that it was not just about the care of my husband but also about my own wellbeing. The facilitator answered all of my questions, and I knew I had a point of call should anything give me cause for concern.

I recall that I was concerned about my husband's breathlessness on one home visit, and the nurse facilitator explained by giving me an analogy of: "You wouldn't expect your car to pull away in fourth gear, you start in first and move slowly through the gears." This made complete sense to me then.

My husband has other comorbidities that affect his walking and general fitness, and this is why the home based exercises are so much better for our situation. We do the chair based exercise DVD together; we are able to pace ourselves and decide which level we start at. We continue with weekly weigh-ins to ensure we keep within healthy limits, and we found the progress tracker helped to monitor progress.

The patient manual itself was a tool that we used-and still use-together. There is a separate manual/resource just for caregivers, which I find very useful.

A video featuring Cindy and Chris Edgeler can be viewed at http://thebmjawards.bmj.com/showcase/.

\section{Additional educational resources for patients and carers}

- American Heart Association: what is cardiac rehabilitation? www.heart.org/en/health-topics/cardiac-rehab/what-is-cardiac-rehabilitation
- Additional information on home based cardiac rehabilitation. www.heart.org/en/news/2019/05/13/experts-urge-expansion-ofhome-based-cardiac-rehabilitation

- A telehealth cardiac rehabilitation programme for patients using a free app to use on a mobile phone/device. www.henryford.com/services/cardiology/support/cardiac-rehab/home-based-cardiac-rehabilitation

- British Heart Foundation: online exercise videos. www.bhf.org.uk/informationsupport/heart-matters-magazine/activity/10-minute-workout

- Online patient education sessions available in six languages. www.healtheuniversity.ca/en/CardiacCollege

- A choice of a book or digital format of a home based programme for patients recovering from a heart attack or revascularisation. https://services.nhslothian.scot/TheHeartManual/Pages/default.aspx

- A webinar on virtual rehabilitation and self-management techniques during covid-19 for people living with heart conditions.

www.heartandstroke.ca/what-we-do/webinars/cardiac-rehab-duringcovid-19

All resources are open access with no registration, except the digital format of the Heart Manual, which requires registration

\section{How this article was created}

We focused on new evidence on home based and telehealth based cardiac rehabilitation that would be of interest to patients, clinicians, and commissioners based on recent publications on the impact of covid-19 and our 2015 clinical review that was co-authored by HD, RST, and PD. RST is a contributor and editor for the Cochrane Heart Group and has led and conducted several systematic reviews of cardiac rehabilitation. These Cochrane reviews have been cited in various national guidelines, which we consulted when writing this article. We referred to annual reports of the National Audit of Cardiac Rehabilitation, which is led by PD, and the BHF website for statistics on coronary heart disease in the UK. We also consulted recent national statements and standards from the UK, US, and Europe, and HD used his personal archive of references.

Acknowledgments: We thank Jemma Lough for help with technical editing of the manuscript, Cindy and Chris Edgeler for patient and care giver involvement, and the Wirral Community Cardiology Service for providing feedback from patients and practitioners involved in the REACH-HF home based programme.

Contributors: HMD conceived the article based on a clinical review he co-authored for TheBM/ in 2015 He contributed to the literature review, drafting, and revising the article and approval of the final version. RST provided details from the various Cochrane systematic reviews that he has led and conducted. PD provided contemporary data from the BHF National Audit of Cardiac Rehabilitation. PD, RST, and SM also contributed to the literature review and drafting, design, and revision of the article. All authors, including patient and public adviser KP, reviewed and approved the final manuscript.

Competing interests: We have read and understood the BMJ policy on declaration of interests and declare the following interests. HMD and PD have also co-authored Cochrane reviews in cardiac rehabilitation with RST. RST is an author on a number of other Cochrane reviews of cardiac rehabilitation. $\mathrm{HMD}$, RST, PD, and KP were co-investigators on the REACH-HF programme of research, which developed and evaluated a home based cardiac rehabilitation intervention for people with heart failure and their carers (NIHR PGfAR RP-PG-0611-12004). South West Academic Health Sciences Network COVID-19 Innovation Adoption Fund provided several two day REACH-HF online facilitator training sessions over summer 2020 (1 May-31 December 2020). British Heart Foundation Hope for Hearts Funding for Digital Rehabilitation Enablement in Chronic Heart Failure (D REACH-HF) (1 July 2020-31/12 /2021). Implementation of an evidence based cardiac rehabilitation home programme for heart failure patients and their care givers in Scotland (SCOT: REACH-HF Project), Heart Research UK, Scotland (1 March 2020-31 August 2021).

Provenance and peer review: Commissioned, based on an idea by the authors; externally peer reviewed

British Heart Foundation. Heart statistics. 2021. www.bhf.org.uk/what-we-do/our-research/heartstatistics.

Piepoli MF, Hoes AW, Agewall S, etalESC Scientific Document Group. 2016 European guidelines on cardiovascular disease prevention in clinical practice: the Sixth Joint Task Force of the European Society of Cardiology and Other Societies on Cardiovascular Disease Prevention in Clinical Practice (constituted by representatives of 10 societies and by invited experts). Developed with the special contribution of the European Association for Cardiovascular Prevention \& Rehabilitation (EACPR). Eur Heart J 2016;37:2315-81. doi: 10.1093/eurhearti/ehw106 pmid: 27222591 
3 British Association for Cardiovascular Prevention and Rehabilitation. The BACPR standards and core components for cardiovascular disease prevention and rehabilitation 2017. 3rd ed. BACPR, 2017.

4 Ambrosetti M, Abreu A, Corra U, etal. Secondary prevention through comprehensive cardiovascular rehabilitation: From knowledge to implementation. 2020 update. A position paper from the Secondary Prevention and Rehabilitation Section of the European Association of Preventive Cardiology. Eur J Prev Cardiol 2020;2047487320913379doi: 10.1177/2047487320913379.

5 Dalal HM, Doherty P, Taylor RS. Cardiac rehabilitation. BM/2015;351:h5000. doi: 10.1136/bmj.h5000 pmid: 26419744

6 Long L, Mordi IR, Bridges C, etal. Exercise-based cardiac rehabilitation for adults with heart failure. Cochrane Database Syst Rev 2019;1:CD003331.

doi: 10.1002/14651858.CD003331.pub5 pmid: 30695817

7 Buckingham SA, Taylor RS, Jolly K, etal. Home-based versus centre-based cardiac rehabilitation: abridged Cochrane systematic review and meta-analysis. Open Heart 2016;3:e000463. doi: 10.1136/openhrt-2016-000463 pmid: 27738516

8 Salzwedel A, Jensen K, Rauch B, etal. Effectiveness of comprehensive cardiac rehabilitation in coronary artery disease patients treated according to contemporary evidence based medicine: Update of the Cardiac Rehabilitation Outcome Study (CROS-II). EurJ Prev Cardio/2020;27:1756-74. doi: 10.1177/2047487320905719 pmid: 32089005

9 Thomas RJ, Beatty AL, Beckie TM, etal. Home-Based Cardiac Rehabilitation: A Scientific Statement From the American Association of Cardiovascular and Pulmonary Rehabilitation, the American Heart Association, and the American College of Cardiology. J Am Coll Cardiol 2019;74:133-53. doi: 10.1016/j.jacc.2019.03.008 pmid: 31097258

10 Ponikowski P, Voors AA, Anker SD, etalAuthors/Task Force MembersDocument Reviewers. 2016 ESC Guidelines for the diagnosis and treatment of acute and chronic heart failure: The Task Force for the diagnosis and treatment of acute and chronic heart failure of the European Society of Cardiology (ESC). Developed with the special contribution of the Heart Failure Association (HFA) of the ESC. Eur J Heart Fail 2016;18:891-975. doi: 10.1002/ejhf.592 pmid: 27207191

11 Yancy CW, Jessup M, Bozkurt B, etal. 2013 ACCF/AHA guideline for the management of heart failure: executive summary: a report of the American College of Cardiology Foundation/American Heart Association Task Force on practice guidelines. Circulation 2013;128:1810-52. doi: 10.1161/CIR.0b013e31829e8807 pmid: 23741057

12 Smith SC, rrBenjamin EJ, Bonow RO, etalWorld Heart Federation and the Preventive Cardiovascular Nurses Association. AHA/ACCF secondary prevention and risk reduction therapy for patients with coronary and other atherosclerotic vascular disease: 2011 update: a guideline from the American Heart Association and American College of Cardiology Foundation. Circulation 2011;124:2458-73. doi: 10.1161/CIR.0b013e318235eb4d pmid: 22052934

13 Chew DP, Scott IA, Cullen L, etal. National Heart Foundation of Australia and Cardiac Society of Australia and New Zealand: Australian clinical guidelines for the management of acute coronary syndromes 2016. Med J Aust 2016;205:128-33. doi: 10.5694/mja16.00368 pmid: 27465769

14 Pesah E, Turk-Adawi K, Supervia M, etal. Cardiac rehabilitation delivery in low/middle-income countries. Heart 2019;105:1806-12. doi: 10.1136/heartjnl-2018-314486 pmid: 31253695

15 Moulson N, Bewick D, Selway T, etal. Cardiac rehabilitation during the covid-19 era: guidance on implementing virtual care. Can J Cardiol 2020;36:1317-21. doi: 10.1016/..cjca.2020.06.006 pmid: 32553606

16 Scherrenberg M, Wilhelm M, Hansen D, etal. The future is now: a call for action for cardiac telerehabilitation in the COVID-19 pandemic from the secondary prevention and rehabilitation section of the European Association of Preventive Cardiology. EurJ Prev Cardiol 2020;2:2047487320939671doi: 10.1177/2047487320939671.

17 British Heart Foundation. National Audit of Cardiac Rehabilitation (NACR) quality and outcomes report 2020. London: BHF, 2020. https://www.bhf.org.uk/informationsupport/publications/statistics/national-audit-of-cardiac-rehabilitation-quality-and-outcomes-report-2020

18 Beatty AL, Bradley SM, Maynard C, MCCabe JM. Referral to cardiac rehabilitation after percutaneous coronary intervention, coronary artery bypass surgery, and valve surgery. Circ Cardiovasc Qual Outcomes 2017;10:e03364

doi: 10.1161/CIRCOUTCOMES.116.003364 pmid: 28619725

19 Ades PA, Keteyian SJ, Wright IS, etal. Increasing cardiac rehabilitation participation from $20 \%$ to 70\%: a road map from the Million Hearts Cardiac Rehabilitation Collaborative. Mayo Clin Proc 2017;92:234-42. doi: 10.1016/j.mayocp.2016.10.014 pmid: 27855953

20 National Cardiac Audit Programme. National Heart Failure Audit: 2020 summary report (2018/19 data). London: NICOR, 2020. https://www.nicor.org.uk/wp-content/uploads/2020/12/NationalHeart-Failure-Audit-2020-FINAL.pdf

21 British Heart Foundation. The National Audit of Cardiac Rehabilitation: quality and outcomes report 2019. London: BHF, 2019. https://www.bhf.org.uk/informationsupport/publications/statistics/national-audit-of-cardiac-rehabilitation-quality-and-outcomes-report-2019

22 Beatty AL, Truong M, Schopfer DW, Shen H, Bachmann JM, Whooley MA. Geographic variation in cardiac rehabilitation participation in Medicare and Veterans Affairs populations: opportunity for improvement. Circulation 2018;137:1899-908. do: 10.1161/CIRCULATIONAHA.117.029471 pmid: 29305529

23 Bjarnason-Wehrens B, McGee H, Zwisler AD, etalCardiac Rehabilitation Section European Association of Cardiovascular Prevention and Rehabilitation. Cardiac rehabilitation in Europe: results from the European Cardiac Rehabilitation Inventory Survey. Eur / Cardiovasc Prev Rehabil 2010;17:410-8. doi: 10.1097/HJR.0b013e328334f42d pmid: 20300001

24 Ritchey MD, Maresh S, McNeely J, etal. Tracking cardiac rehabilitation participation and completion among Medicare beneficiaries to inform the efforts of a national initiative. Circ Cardiovasc Qual Outcomes 2020;13:e005902. doi: 10.1161/CIRCOUTCOMES.119.005902 pmid: 31931615
25 Arena R, Williams M, Forman DE, etalAmerican Heart Association Exercise, Cardiac Rehabilitation and Prevention Committee of the Council on Clinical Cardiology, Council on Epidemiology and Prevention, and Council on Nutrition, Physical Activity and Metabolism. Increasing referral and participation rates to outpatient cardiac rehabilitation: the valuable role of healthcare professionals in the inpatient and home health settings: a science advisory from the American Heart Association. Circulation 2012;125:1321-9. doi: 10.1161/CIR.0b013e318246b1e5 pmid: 22291128

26 Clark RA, Conway A, Poulsen V, Keech W, Tirimacco R, Tideman P. Alternative models of cardiac rehabilitation: a systematic review. Eur J Prev Cardiol 2015;22:35-74. doi: 10.1177/2047487313501093 pmid: 23943649

27 National Institute for Health and Care Excellence. Chronic heart failure in adults: diagnosis and management. NICE Guideline NG106. London: NICE, 2018. https://www.nice.org.uk/guidance/ng106

28 O'Connor CM, Whellan DJ, Lee KL, etalHF-ACTION Investigators. Efficacy and safety of exercise training in patients with chronic heart failure: HF-ACTION randomized controlled trial. JAMA 2009;301:1439-50. doi: 10.1001/jama.2009.454 pmid: 19351941

29 Frederix I, Caiani EG, Dendale P, etal. ESC e-Cardiology Working Group Position Paper: Overcoming challenges in digital health implementation in cardiovascular medicine. Eur J Prev Cardiol 2019;26:1166-77. doi: 10.1177/2047487319832394 pmid: 30917695

30 Thomas E, Gallagher R, Grace SL. Future-proofing cardiac rehabilitation: Transitioning services to telehealth during COVID-19. EurJ Prev Cardiol 2020:2047487320922926doi: 10.1177/2047487320922926

31 Krug E, Cieza A. Strengthening health systems to provide rehabilitation services. Bull World Health Organ 2017;95:167. doi: 10.2471/BLT.17.191809 pmid: 28250526

32 NHS England. NHS long term plan. London: NHS England; 2019 [https://www.longtermplan.nhs.uk/online-version/chapter-3-further-progress-on-care-qualityand-outcomes/better-care-for-major-health-conditions/cardiovascular-disease/.

33 Dalal H, Taylor RS, Greaves C, etalREACH-HF Study Group. Correspondence to the EJPC in response to position paper by Ambrosetti $M$ et al. 2020: Cardiovascular rehabilitation and COVID-19: The need to maintain access to evidence-based services from the safety of home. Eur J Prev Cardiol 2020;2047487320923053. doi: 10.1177/2047487320923053. pmid: 32340485

34 American Association of Cardiovascular and Pulmonary Rehabilitation. Coronavirus resources. 2020 www.aacvpr.org/covid19.

35 Gravely-Witte S, Leung YW, Nariani R, etal. Effects of cardiac rehabilitation referral strategies on referral and enrollment rates. Nat Rev Cardiol 2010;7:87-96. doi: 10.1038/nrcardio.2009.223 pmid: 19997077

36 Thomas RJ, King M, Lui K, Oldridge N, Piña IL, Spertus JWriting Committee Members. AACVPR/ACCF/AHA 2010 Update: performance measures on cardiac rehabilitation for referral to cardiac rehabilitation/secondary prevention services. Circulation 2010;122:1342-50. doi: 10.1161/CIR.0b013e3181f5185b pmid: 20805435

37 Hinde S, Bojke L, Harrison A, Doherty P. Improving cardiac rehabilitation uptake: Potential health gains by socioeconomic status. Eur J Prev Cardiol 2019;26:1816-23. doi: 10.1177/2047487319848533 pmid: 31067128

38 Al Quait A, Doherty P, Gutacker N, Mills J. In the modern era of percutaneous coronary intervention: Is cardiac rehabilitation engagement purely a patient or a service level decision?Eur] Prev Cardiol 2017:24:1351-7. doi: 10.1177/2047487317717064 pmid: 28633533

39 Eberly LA, Khatana SAM, Nathan AS, etal. Telemedicine outpatient cardiovascular care during the COVID-19 pandemic: bridging or opening the digital divide?Circulation 2020;142:510-2. doi: 10.1161/CIRCULATIONAHA.120.048185 pmid: 32510987

40 Health Education England. The Topol review: preparing the healthcare workforce to deliver the digital future. London: Health Education England, 2019. https://topol.hee.nhs.uk/wp-content/uploads/HEE-Topol-Review-2019.pdf

41 Dalal HM, Taylor RS. Telehealth technologies could improve suboptimal rates of participation in cardiac rehabilitation. Heart2016;102:1155-6. doi: 10.1136/heartjn-2016-309429 pmid: 27067360

42 Doherty P, Harrison A. Investigation of the impact of covid-19 on UK CR: what can we learn from this experience? Oral presentation at the BACPR annual online conference, 2020.

43 Mafham MM, Spata E, Goldacre R, etal. COVID-19 pandemic and admission rates for and management of acute coronary syndromes in England. Lancet 2020;396:381-9. doi: 10.1016/S0140-6736(20)31356-8 pmid: 32679111

44 O'Doherty AF, Humphreys H, Dawkes S, etal. How has technology been used to deliver cardiac rehabilitation during the COVID-19 pandemic? An international cross-sectional survey of healthcare professionals conducted by the BACPR. BMJ Open 2021;0:e046051.

45 National Institute for Health and Care Excellence. COVID-19 ready rehabilitation for heart failure: REACH-HF can deliver. 2020. https://www.nice.org.uk/sharedlearning/covid-19-ready-rehabilitation-for-heart-failure-reach-hf-can-deliver

46 National Institute for Health and Care Excellence. Delivering Rehabilitation EnAblement in CHronic Heart Failure (REACH-HF) in Wirral. 2021. https://www.nice.org.uk/sharedlearning/delivering-rehabilitation-enablement-in-chronic-heart-failure-reach-hf-in-wirral

47 Dawkes S, Hughes S, Ray S, etal. Covid-19 and cardiac rehabilitation. Br J Cardiol 2020;27:79. 
48 Arena R, Myers I, Williams MA, etalAmerican Heart Association Committee on Exercise, Rehabilitation, and Prevention of the Council on Clinical CardiologyAmerican Heart Association Council on Cardiovascular Nursing. Assessment of functional capacity in clinical and research settings: a scientific statement from the American Heart Association Committee on Exercise, Rehabilitation, and Prevention of the Council on Clinical Cardiology and the Council on Cardiovascular Nursing. Circulation 2007:116:329-43.

doi: 10.1161/CIRCULATIONAHA.106.184461 pmid: 17576872

49 Vishwanath V, Beckman AL, Kazi DS. Reimagining cardiac rehabilitation in the era of coronavirus disease 2019. JAMA Health Forum 2020;1:e201346doi: 10.1001/jamahealthforum.2020.1346.

50 Imran HM, Baig M, Erqou S, etal. Home-based cardiac rehabilitation alone and hybrid with center-based cardiac rehabilitation in heart failure: a systematic review and meta-analysis. J Am Heart Assoc 2019;8:e012779. doi: 10.1161/JAHA.119.012779 pmid: 31423874

51 Taylor RS, Walker S, Smart NA, etalExTraMATCH II Collaboration. Impact of exercise rehabilitation on exercise capacity and quality-of-life in heart failure: individual participant meta-analysis. J Am Coll Cardiol 2019;73:1430-43. doi: 10.1016/j.jacc.2018.12.072 pmid: 30922474

52 Wingham J, Dalal HM, Sweeney KG, Evans PH. Listening to patients: choice in cardiac rehabilitation. Eur J Cardiovasc Nurs 2006;5:289-94. doi: 10.1016/j.ejcnurse.2006.02.002 pmid: 16545616

53 Schopfer DW, Krishnamurthi N, Shen H, Duvernoy CS, Forman DE, Whooley MA. Association of Veterans Health Administration home-based programs with Access to and participation in cardiac rehabilitation. JAMA Intern Med 2018;178:715-7.

doi: 10.1001/jamainternmed.2017.8039 pmid: 29356813

54 Shields GE, Wells A, Doherty P, Heagerty A, Buck D, Davies LM. Cost-effectiveness of cardiac rehabilitation: a systematic review. Heart 2018;104:1403-10. doi: 10.1136/heartjnl-2017-312809 pmid: 29654096

55 Taylor RS, Sadler S, Dalal HM, etal. The cost effectiveness of REACH-HF and home-based cardiac rehabilitation compared with the usual medical care for heart failure with reduced ejection fraction: A decision model-based analysis. Eur J Prev Cardiol 2019;26:1252-61.

doi: 10.1177/2047487319833507 pmid: 30884975

56 Dalal HM, Taylor RS, Wingham J, et al. A facilitated home-based cardiac rehabilitation intervention for people with heart failure and their caregivers: a research programme including the REACH-HF RCT. NIHR PGFAR 2021. doi: 10.3310/pgfar09010
57 Maddison R, Rawstorn JC, Stewart RAH, etal. Effects and costs of real-time cardiac telerehabilitation: randomised controlled non-inferiority trial. Heart 2019;105:122-9. doi: 10.1136/heartjnl-2018-313189 pmid: 30150328

58 Jin K, Khonsari S, Gallagher R, etal. Telehealth interventions for the secondary prevention of coronary heart disease: A systematic review and meta-analysis. Eur J Cardiovasc Nurs 2019;18:260-71. doi: 10.1177/1474515119826510 pmid: 30667278

59 Rawstorn JC, Gant N, Direito A, Beckmann C, Maddison R. Telehealth exercise-based cardiac rehabilitation: a systematic review and meta-analysis. Heart 2016;102:1183-92. doi: 10.1136/heartinl-2015-308966 pmid: 26936337

60 National Institute for Health Research. A randomised controlled trial of a facilitated home-based rehabilitation intervention in patients with heart failure with preserved ejection fraction and their caregivers: the REACH-HFpEF Study. 2021. https://fundingawards.nihr.ac.uk/award/NIHR130487

61 Norekvål TM, Allore HG, Bendz B, etalCONCARD Investigators. Rethinking rehabilitation after percutaneous coronary intervention: a protocol of a multicentre cohort study on continuity of care, health literacy, adherence and costs at all care levels (the CONCARD ${ }^{\mathrm{PCl}}$ ). BMJ Open 2020;10:e031995. doi: 10.1136/bmjopen-2019-031995 pmid: 32054625

62 Dodson JA, Hajduk AM, Murphy TE, etal. Thirty-day readmission risk model for older adults hospitalized with acute myocardial infarction. Circ Cardiovasc Qual Outcomes 2019;12:e005320 doi: 10.1161/CIRCOUTCOMES.118.005320 pmid: 31010300

63 Clinicaltrials.gov. The Improving ATTENDance in Cardiac Rehabilitation Trial (iATTEND). 2020. https://clinicaltrials.gov/ct2/show/NCT03646760.

64 Taylor RS, Singh S. Personalised rehabilitation for cardiac and pulmonary patients with multimorbidity: Time for implementation?Eur J Prev Cardiol 2020;16:2047487320926058.

This is an Open Access article distributed in accordance with the terms of the Creative Commons Attribution (CC BY 4.0) license, which permits others to distribute, remix, adapt and build upon this work, for commercial use, provided the original work is properly cited. See: http://creativecommons.org/licenses/by/4.0/.

\section{Interventions}

uat

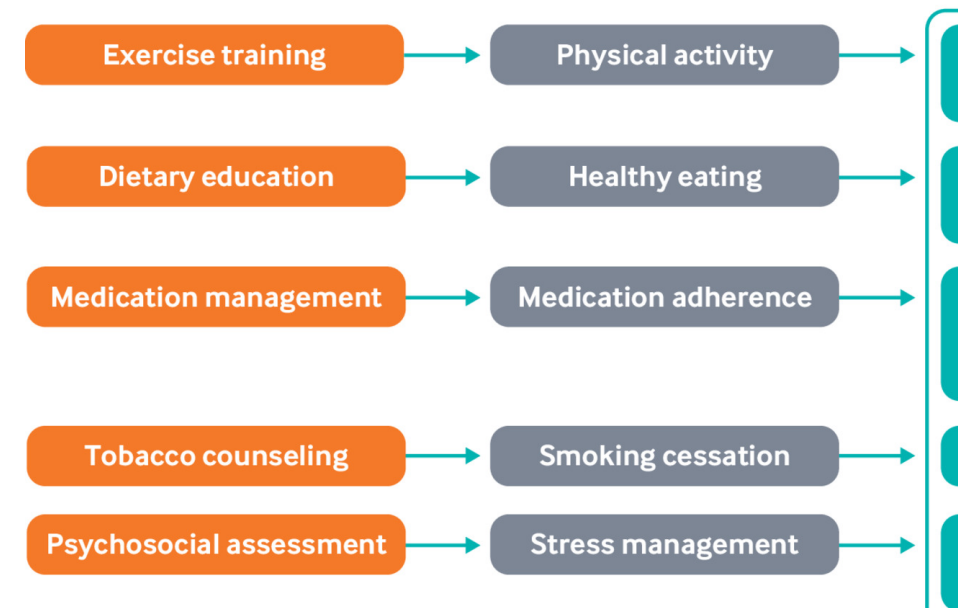

Intermediate outcomes
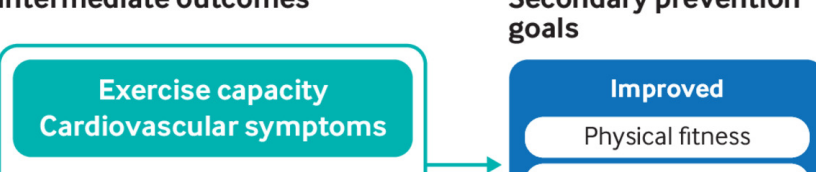

Body mass index

Waist circumference

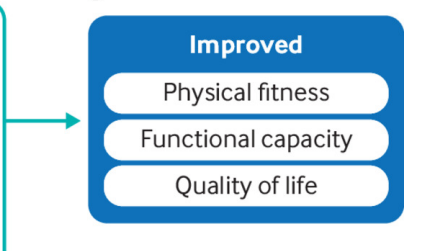

Blood pressure

Glycaemic control

Lipid levels

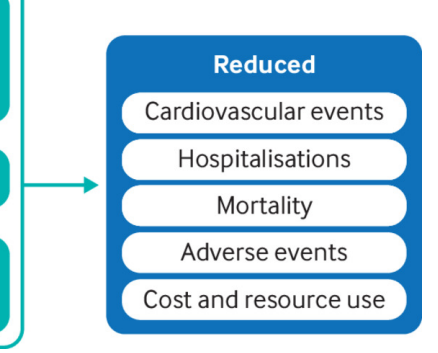

Tobacco use

Stress management $\longrightarrow \underset{\begin{array}{c}\text { Anxiety } \\ \text { Depression }\end{array}}{\longrightarrow}$

Stress management $\longrightarrow \longrightarrow \begin{gathered}\text { Anxiety } \\ \text { Depression }\end{gathered}$

Fig 1 | Structure, process, and outcome metrics for home based cardiac rehabilitation. Reproduced with permission ${ }^{9}$ 